\title{
Profit from Sickness: The Case of Technology-Driven Healthcare
}

\author{
Suman Hazarika ${ }^{1}$, Akhil Ranjan Dutta $^{2}$ \\ ${ }^{1}$ Department of Radiology, International Hospital, Guwahati, India \\ ${ }^{2}$ Department of Political Science, Gauhati University, Guwahati, India \\ Email: sumanhazarika@rediffmail.com
}

Received July 26 ${ }^{\text {th }}, 2012$; revised August 29 $9^{\text {th }}, 2012$; accepted September $13^{\text {th }}, 2012$

\begin{abstract}
The increasing corporatization and growing dependence of the healthcare system on technology has brought about a radical transformation to the entire mission of the healthcare system. Based on the profit motive, the pharmaceutical and technological enterprises that hugely control the healthcare system today have so transformed the system that it has now emerged as one of the most profiteering domains. The historical tragedy is that the profit is earned over sickness. There has indeed been an attempt to generate sickness as demanded both by health care devices as well as by the pharmaceutical industries having detrimental impact on people's right to health. Present paper, which critically questions the logic and motives of the emerging healthcare system, argues that under the contemporary neo-liberal economies, diseases and patients are objects of business interests of the largely privatized for-profit healthcare industry. Profit from these objects emerges not only through sale of drugs or cure, but also from expensive hi-tech testing and "treatment" technologies. Creation of new patients by diagnosing more diseases to treat is contributed by a large medical-industrial complex today. The paper is of the view that remedies to these crises demand radical a U-turn to the system itself wherein the health care seekers rather than the health care providers would occupy the center stage.
\end{abstract}

Keywords: Epidemics; Pharmaceutical Industry; Medical-Industrial Complex; Mass Killer; Cocktail Vaccines

\section{Introduction}

Concerned with less than adequate quality of medical education and the consequent degradation of the healthcare system of America, in the early part of 20th century, Abraham Flexner, an educationist, was commissioned by the Carnegie Foundation to systematically review the state of medical education in the American continent. After a thorough study and visit to all the medical schools of the United States of America and Canada, he submitted a report in 1910. His 1910 report, Medical Education in the United States and Canada, is a classic work often cited for its importance even today. Flexner's report fueled change by criticizing the mediocre quality and profit motive of many schools and teachers, the inadequate curricula and facilities at a number of schools, and the non-scientific approach to preparation for the profession (Cooke, Irby, Sullivan, \& Ludmerer, 2006). Based on Flexner's observation, a massive shift in the ways of medical education had ensued and over the next few decades, the medical education system evolved into one of the finest in the world. However, one of the concerns expressed in Flexner's observation on the medical education and healthcare system regarding the motive to profit affecting its quality seems to persist even after a century. Current scenario in the healthcare system has precipitated pressure on physicians to increase their clinical productivity; that is, to generate revenues by providing care for paying patients. Mounting clinical chores leave less time for the academic pursuit of the medical sciences. Market-driven economy has brought in the health administrators and managers to manage the for-profit healthcare system. Changing the care delivery system to an industry that sales its service, nevertheless, has created its own evils. Today, healthcare managers think in terms of "patient throughput", "market share", "bed occupancy", "wait time", "utilization rate", and finally, "return on investment". It has become a culture of business rather than a culture of service.

In a world polarized by economic divide, health care facilities are built by entrepreneurs to earn money. Today, giant pharmaceutical corporations are some of the most profitable companies with unimaginable power over the healthcare system and people. It is time to see how healthcare has evolved into an industry seeking big profits at any cost.

\section{Perspective on Being Sick and Sickness of Body}

In the contemporary neoliberal economies, diseases and patients are objects of business interest of the largely privatized for-profit healthcare industry. Profit from these objects emerges not only through sale of drugs or cure, but also from expensive hi-tech testing and "treatment" technologies. Creation of new patients by diagnosing more diseases to treat is contributed by a large medical-industrial complex of diagnostic technologies such as the expensive CT scan, MRI, ultrasound equipment, and more sophisticated and evolving laboratory medical technologies like molecular diagnostics, electron microscopy so on and so forth.

While technology-driven modern medical care tends to analyze the functionality of bodily organs to repair or restore them to the best possible level, it also reduces the human being into biological machines in need of repair.

\section{Evolution of Medical-Industrial Complex}

In 1980, Relman in his essay on medical-industrial complex, argued that silent rise of investor-owned businesses was taking 
over large parts of a health system, which until then had been largely community-based and not-for-profit (Relmam, 1980). The constituent of the system included proprietary hospitals and nursing homes, diagnostic laboratories, home care and emergency room services, and hemodialysis centers. Relman has cited similarity of the healthcare system to the "military-industrial complex" that Dwight Eisenhower had warned about in his farewell address as US president in 1961. The expression "new medical-industrial complex" was coined by Relman, and today it is in popular use. This new medical-industrial complex may be seen as more efficient than its nonprofit competition, but it also has the serious problem of overuse and fragmentation of services, overemphasis on technology, and undue influence on health policy. In his 1997 paper Market for healthcare: where is the patient? Relman observes, "Markets may be efficient ways of distributing goods and services to those who can afford them, but they are quite indifferent to the needs of the poor and underprivileged". There is increasing presence of for-profit players in the healthcare system and unless the medical-industrial complex is regulated properly, a people friendly system based on compassion and need cannot be built. Relman has expressed his concern in this regards, “... new medicalindustrial complex defined to include the entire range of businesses concerned with the delivery of health services, probably now accounts for at least $50 \%$ of total national (American) expenditures on personal healthcare. It is undoubtedly the most powerful element shaping our health care system today. No significant reform can be expected in the future without regulation of the market forces now dominant in that system." (Relman, 1997).

Based on his study of the American healthcare system, Paul Starr, in 1982, predicted the reduction of public healthcare system by the evolving corporate health industry in his book titled Social Transformation of American Medicine (Starr, 1982). His prediction was that, "Instead of public regulation, there will be private regulation, and instead of public planning, there will be private planning. Instead of public financing for prepaid plans there will be corporate financing for private plans controlled by conglomerates whose interest will be determined by the rate of return on investments".

Geyman, in 2003, in a paper titled Corporate Transformation of Medicine and its Impact on Cost and Access to Care, has commented that the full impact of the medical-industrial complex over American healthcare system has been obvious with increasing cost of health care, over dependence on technology and inefficiency (Geyman, 2003). Geyman observed that for investor-owned health care corporations, money is the mission, not the public interest. The flaws of an unregulated market system have been exposed, but lamentably, public and professsional understanding of these issues is not forthcoming.

\section{Rising Health Care Cost: Rising Profit from Sickness?}

In 1986, the Institute of Medicine published its study on forprofit enterprises in health care that focused primarily on the behavior of investor-owned acute care hospitals (Gray, 1986). The highlights of the study were that investor-owned hospitals increased health care costs to the payers; these establishments provided less charity care and were not any more efficient than not-for-profit hospitals.

There are comparative studies trying to understand difference in standard of care between private for-profit medical facilities versus state-owned nonprofit facilities. In the cases of chronic kidney disease or end stage kidney disease, modern dialysis technique extends life span. Dialysis, per say, is an expensive and high-end technology that maintains internal chemistry of a person whose kidneys are not working properly. Reliable studies reveal that death rates differ in profit seeking versus nonprofit enterprises that provide dialysis care for end stage renal disease. The New England Journal of Medicine in 1999 carried an article titled Effect of ownership of dialysis centres on patient survival (Garg, Frick, Diener, \& Powe, 1999). It was seen in this study on 3569 patient with end stage renal disease that crude mortality rate per 100 person-years was 21.2 in for-profit facilities, as compared to 17.1 in not-for-profit facilities. It was further seen that even after adjusting the variables of the patient etc. treatment in a for-profit facility continued to be associated with higher mortality rate.

In a meta-analysis published in the Journal of American Medical Association in 2002 about dialysis facilities, it was concluded that mortality rates are higher in private for-profit dialysis centers than the nonprofit dialysis units. The authors identified lack of adequate work force and reduced length of dialysis time as the chief culprits that had a negative effect on patients. Profit motives of private for-profit centers resulted in these flawed practices (Devereaux, Schünemann, Ravindran, Bhandari, Garg, Choi et al., 2002).

Reduction of hemoglobin (anemia) in chronic kidney disease is a recognized phenomenon. The introduction of recombinant human erythropoietin (epoetin) ${ }^{1}$ in 1989 significantly improved the clinical management of anemia in cases of the end-stage kidney disease. This drug is very costly and it is found to be the largest single Medicare drug expenditure totaling $\$ 1.8$ billion in the USA in 2004 (United States Renal Data System, 2006). It was found that for-profit facilities administered smaller doses of epoetin compared with nonprofit facilities, due to the cost of the medicine in the early days. Once epoetin payment has been based on the amount of drug administered creating a financial incentive for increased use of this therapy, it was seen that the use of this drug started to increase. Thamer et al. in 2007 published a study titled Dialysis Facility Ownership and Epoetin Dosing in Patients on Haemodialysis in the Journal of American Medical association (Thamer, Zhang, Kaufman, Cotter, Dong, \& Hernán, 2007). This study suggested a profit motive in deciding drug dosing in end-stage kidney disease patient. The researchers included adult Medicare eligible end-stage renal disease patients receiving in-center hemodialysis during November and December 2004. Regression models were used to estimate the mean epoetin dose and dose adjustment by profit, chain, and affiliation status. The study included 28,199 patients from nonprofit dialysis centers and 159,522 patients from the for-profit dialysis centers. The study documented consistently higher dosing of epoetin in the for-profit centers. In the concluding remark, the authors commented that dialysis facility organizational status and ownerships are associated with variation in epoetin doses in United States. The researchers put the final comment to highlight the need for a rational reimburse-

\footnotetext{
${ }^{1}$ Erythropoietin is normally produced by kidneys, and they regulate blood hemoglobin. Kidney diseases alter the balance of erythropoietin and hemoglobin production. It is a medical practice now to use erythropoietin produced artificially by recombinant DNA technology to regulate the hemoglobin levels in patients of chronic kidney disease. Epoetin is one of the commercially produced erythropoietin.
} 
ment policy that provides an incentive to achieve desired clinical outcomes while optimizing epoetin usage.

It is not very difficult to imagine that in the dominant capitalist world economy, there is an ever-increasing cost escalation in providing health care due to cost of technology. In today's technology dominant health care delivery, the act of medical diagnosis and treatment of illness is increasingly seen as big business. Sick bodies are objects of exploitation for the promotion of new medical drugs and technologies. To support our conjecture of big business, we cite the interesting statistics in Table 1, which is detailing the annual revenue and profits of the big pharmaceuticals company in the years of 2006, 2008, 2010. All these companies consistently figured in the Fortune magazine's list of top companies (Fortune Magazine, April 17th 2006, May 5th 2008 and May 3rd issues of 2010).

The pharmaceutical industry argues that its high drug prices are necessary for innovation and development of new drugs, but the evidence is overwhelming that unrestrained profiteering has been the rule for many years. A further look at the profit versus expenditure incurred for new developments and research is necessary at this point. We are presenting the research and development cost as a percentage of the revenue of the few big pharmaceutical industries in Table 2, based on their annual reports from the archive (Fortune 500 database of 50 years) and published reports (Davidson \& Greblov, 2005).

The $R \& D$ costs as fraction of the revenue earned appear to be acceptable in a superficial look, but it is deceptive to accept at face value. One needs to be critical in approaching the data on $R \& D$ cost based on the fact that relatively low number of actual new molecules or active drugs are invented out of these research activities compared to combination products or variations in the existing blockbuster drugs. In the USA, the entry of a new drug to the market is strictly regulated by the Food and Drug Administration (FDA). In their May 2002 report, National Institute of Healthcare Management cites the interesting statistics from the FDA records about new drug approvals (NIHCM, 2002). Between 1989 and 2000, the FDA approved 1035 new drug applications. Of these, 361 or $35 \%$ were for actually new active ingredients. In the same period, $65 \%$ medicines were approved that were already available and marketed products.

Table 1.

Comparison of revenue, profit and profit as percentage of revenue in 2006, 2008, and 2010 of six fortune 500 pharmaceutical companies.

\begin{tabular}{|c|c|c|c|c|c|c|}
\hline \multirow{2}{*}{ Revenue \& Profit in Million \$ } & \multicolumn{6}{|c|}{ Company Name } \\
\hline & Johnson \& Johnson & Pfizer & Merck & Bristol Meyer's Squibb & Wyeth & Eli Lilly \\
\hline \multicolumn{7}{|l|}{2006} \\
\hline Revenue Total & 50,514 & 51,353 & 22,012 & 20,222 & 18,756 & 14,645 \\
\hline Profit Total & 10,411 & 8085 & 4531 & 3000 & 3656 & 1980 \\
\hline Profit as $\%$ of Revenue & $21 \%$ & $16 \%$ & $21 \%$ & $15 \%$ & $20 \%$ & $14 \%$ \\
\hline \multicolumn{7}{|l|}{2008} \\
\hline Revenue Total & 61,095 & 48,418 & 24197.7 & 19977.7 & 22399.8 & 18633.5 \\
\hline Profit Total & 10,576 & 8144 & 3275.4 & 2165 & 4616.0 & 2953.0 \\
\hline Profit as $\%$ of Revenue & $17 \%$ & $16.8 \%$ & $13.5 \%$ & $10.4 \%$ & $20.6 \%$ & $15.8 \%$ \\
\hline \multicolumn{7}{|l|}{2010} \\
\hline Revenue Total & 61,897 & 50,009 & 27428.3 & 21,634 & Not Available & 21,863 \\
\hline Profit Total & 12,266 & 8635 & 12901.3 & 10,612 & & 4328.8 \\
\hline Profit as $\%$ of Revenue & $19 \%$ & $17.3 \%$ & $47 \%$ & $49.1 \%$ & & $19.8 \%$ \\
\hline
\end{tabular}

Table 2.

R\&D costs and profit of pharmaceutical industry as percentage of total revenues.

\begin{tabular}{|c|c|c|c|c|}
\hline \multirow{2}{*}{ Company Name } & \multirow{2}{*}{ R\&D Expenditure and Profit } & \multicolumn{3}{|c|}{ Year } \\
\hline & & 2002 & 2003 & 2004 \\
\hline \multirow{2}{*}{ Pfizer } & R\&D Cost as \% of Revenue & $16.1 \%$ & $16.7 \%$ & $14.6 \%$ \\
\hline & Profit as \% Revenue & $24.1 \%$ & $25.9 \%$ & $8.5 \%$ \\
\hline \multirow{2}{*}{ Johnson \& Johnsons } & R\&D Cost as $\%$ of Revenue & $10.9 \%$ & $11.2 \%$ & $11 \%$ \\
\hline & Profit as $\%$ Revenue & $17.2 \%$ & $18.2 \%$ & $17.4 \%$ \\
\hline \multirow{2}{*}{ Merck } & R\&D Cost as $\%$ of Revenue & $5.2 \%$ & $14.6 \%$ & $17.5 \%$ \\
\hline & Profit as \% Revenue & $15.3 \%$ & $13.8 \%$ & $30.4 \%$ \\
\hline \multirow{2}{*}{ Bristol Meyers Sqibb } & R\&D Cost as \% of Revenue & $12.2 \%$ & $10.9 \%$ & $12.9 \%$ \\
\hline & Profit as $\%$ Revenue & $24.2 \%$ & $10.5 \%$ & $14.3 \%$ \\
\hline \multirow{2}{*}{ Wyeth } & R\&D Cost as \% of Revenue & $14.3 \%$ & $13.2 \%$ & $14.2 \%$ \\
\hline & Profit as $\%$ of Revenue & $16.2 \%$ & $30.5 \%$ & $12.9 \%$ \\
\hline
\end{tabular}


Similarly, from 1989 to 2000, the FDA gave a priority review to $24 \%$ of new drug applications that appeared to be of importance due to the fact they were possibly improvements on existing therapy. FDA data is a clear indication to the direction of research in pharmaceutical industry. We shall further argue in our paper about negligence of the "poor men disease" where little research funding is spared because possible profit from these research is considered to be low. In reality, much of the $\mathrm{R} \& \mathrm{D}$ is devoted to repackaging or recombining already available or invented drugs rather than spending a fortune on possibility of finding cure for yet to be treated diseases. There is no doubt that new drug design and development is a long arduous procedure, which will be following long routes of phased clinical trials before being released to the market, but one cannot deny the fact that even if the costs to treat is high and process is arduous, we need to focus on many of the tropical diseases affecting the so-called developing nations. There cannot be denial of health and life based on cost involved in research and production to the marginalized poorer nations of the world. The drug industry has the responsibility to fund more research into low cost solutions of various infective diseases that affect the developing nations.

In 1950, Senator Estes Kefauver headed the United State's Anti-Trust and Monopoly Subcommittee to examine the business model of the pharmaceutical industry. Kefauver brought in the charge of predatory drug prices and excessive margins of the pharmaceutical industry that is born by the patient (Kefauver, 1965). The next two important charges were concerning the extravagant expenditures in marketing that drives cost of medicine and introduction of not so effective newer products. Since then, there have been continuing debates on excess profit versus research expenditures of the drug manufacturing industry. There have been counter views from the industry sides showing more cost in R\&D than their expenditure on marketing, but the methods of accountings are complex. Researchers have continued to examine the marketing and promotional expenditures from various business intelligence reports and published annual reports to examine the issue of massive promotional expenditures against reduced $R \& D$ budget. Gagnon, M. A. (2008) remarked in the final conclusion of the study titled "The Cost of Pushing Pills: A New Estimate of Pharmaceutical Promotion Expenditures in the United States", “... numbers clearly show how promotion predominates over $R \& D$ in the pharmaceutical industry, contrary to the industry's claim. While the amount spent on promotion is not in itself a confirmation of Kefauver's depiction of the pharmaceutical industry, it confirms the public image of a marketing-driven industry and provides an important argument to petition in favor of transforming the workings of the industry in the direction of more research and less promotion." (Gagnon \& Lexchin 2008).

While the pharmaceutical industry has been identified as a big spender in advertising and promotional activities millions are left waiting for a cure to be found for various neglected tropical disease. In 2002, the Fortune 500 pharmaceutical companies spent nearly $30.8 \%$ of their revenue in advertising and marketing in contrast to $14.1 \%$ on R\&D activity (Public Citizen, 2003). The question what is being researched and for whom it is being researched needs to be answered too. In terms of total corporate expenditure, sales and marketing account for the greatest corporate expense and rose from $28.7 \%$ to $33.1 \%$ of expenditure between 1995 and 2005 (Johnston, Moss, \& Brown,
2011).

A historical review of changing values illustrates the rising profit motives from sickness. In the bygone days of global polio epidemics, Jonas Salk \& Albert Sabin discovered the polio vaccines in the 1950s, and the world avoided a huge number of polio deaths. Polio is being eradicated today, and the inventor duo of the vaccine refused to patent the vaccine for earning their share of profit, made it a gift to humanity. The idea of earning profit from a discovery to treat a disease was alien to them!

Stomach ulcer, as we all call it, was being treated by costly medicines that were used to treat the pain and symptoms, far from curing the ulcer itself. Barry Marshall discovered a bacterium called $H$. pylori that causes the stomach ulcer in 1984, but nobody bothered to treat ulcers with antibiotic for another decade. Dr Marshall's initial claim of bacteria causing stomach ulcer was initially not accepted by the fraternity. Dr Marshall was unable to make his case in studies with lab mice (because, H. pylori affects only primates) and prohibited from experimenting on people, Dr. Marshall grew desperate. Finally, he ran an experiment on himself. He infected himself by taking $\mathrm{H}$. pylori from the gut of an ailing patient, stirred it into a broth, and drank it. After 10 days, he biopsied his own stomach and found $H$. pylori proving unequivocally that bacteria were the underlying cause of ulcers. In an interview Dr Marshall commented, "In fact, our letters (to Lancet Magazine) were so weird that they almost didn't get published. By then, I was working at a hospital in Fremantle, biopsying every patient who came through the door. I was getting all these patients and couldn't keep tabs on them, so I tapped all the drug companies to request research funding for a computer. They all wrote back saying how difficult times were and they didn't have any research money. But they were making a billion dollars a year for the antacid drug Zantac and another billion for Tagamet. You could make a patient feel better by removing the acid. Treated, most patients didn't die from their ulcer and didn't need surgery, so it was worth $\$ 100$ a month per patient, a hell of a lot of money in those days. In America in the 1980s, 2 to 4 percent of the population had Tagamet tablets in their pocket. There was no incentive to find a cure." (Weintraub, 2010). The powerful industries making huge profits from ulcers were simply not interested in curing their customers (patients) if it meant losing their margins of profits. In 1997, massive government campaigns were needed to popularize treatment of stomach ulcers with a short course antibiotic that is cheaper than treating the symptoms by costly drugs for years. The very fact that the medical-industrial complex neglected a discovery that produces effective and cheaper cure for stomach ulcers for nearly 15 years, prompts us to raise questions regarding motive of the medical-industry.

The story of $\mathrm{H}$. pylori and stomach ulcer is cited to drive home the point that corporate health industry might not act on the best interest of a patient, if it affects their profit from sales of existing products. It is entirely possible to suppress useful research findings. How do we know today that a cheaper treatment method or therapy for a mass killer like HIV or cancer has not already been invented? Can we trust the medical industry to sacrifice profit and investments to encourage treatments that can make the current costly drugs redundant? Will such an invention reach the public immediately, or is there a possibility of hiding facts concerning new developments? Will the medical-industry complex suppress and brush aside the genuine 
claims, or find complex arguments to banish newer alternatives as was done for the cure of stomach ulcer?

These are very powerful thoughts centering the very idea of building a healthcare system to earn profit. One should reflect on the possibility of such enterprises maximizing profit and minimizing health of the people.

\section{HIV and the Fallout: Reducing Cost of Big Pharma Products by Generic Drugs}

AIDS epidemic has successfully recruited human endeavor for profit too. Like all other global diseases, HIV created opportunity to make the big profit. In 2007, drug major Gilead made \$1194 million sales turnover from selling Truvada-a drug for HIV, which was a whopping $210 \%$ climb from their 2005 sales. Table 3 presents the worldwide sales turnover of a few important anti-AIDS medications (Treatment Action Group, 2007).

The high prices of AIDS drugs started the worldwide debate in the socio-political circles. Dr. Nathan Ford, in his 2003 British Medical Journal essay, cites Dr. Chris Ouma of Kenya, where 2.5 million people are infected with HIV, and most of them cannot afford AIDS drugs, "The doctor's role goes from caregiver to undertaker. You talk to them about the cheapest method of burial. Telling them about the drugs is always kind of a cruel joke." (Ford, 2003).

The global epidemic of HIV and AIDS have seen lots of political activism and participation of the public to debate the issues of high cost of treatment of HIV infection and the possible consequence of an pandemic. Because of public outrage, big pharmaceutical companies agreed on differential pricing of HIV drugs for the low-income countries and gave birth to generic drugs. Cipla, an Indian pharmaceutical company, started to produce generic anti-retrovirals that were the same as those made by large pharmaceutical companies, but significantly cheaper due to lesser expenses related to research and development. Generic drug created a price war that forced the large pharmaceutical companies to lower the price of their AIDS drugs. Generic drug started a new race in the game to protect the interests of the big pharmaceutical companies. They argued that without a patent to their researched drug or product, they could not sustain the research activity to discover new drugs or devices, let alone send them for multistage clinical trials. A drug patent typically lasts for 20 years.

Table 3.

Anti-HIV drug sales volume of top companies in 2006.

\begin{tabular}{cccc}
\hline Drug & Company & $\begin{array}{c}\text { Sales Volume } \\
\text { in Million } \$\end{array}$ & $\begin{array}{c}\text { Change from } \\
2005\end{array}$ \\
\hline Truvada & Gilead & 1194 & $+210 \%$ \\
Kaletra & Abbott & 1135 & $+13 \%$ \\
Combivir & GlaxoSmithKline & 977 & $-8 \%$ \\
Reyataz & $\begin{array}{c}\text { Bristol-Myers } \\
\text { Squibb }\end{array}$ & 931 & $+34 \%$ \\
Sustiva & $\begin{array}{c}\text { Bristol-Myers } \\
\text { Squibb }\end{array}$ & 791 & $+16 \%$ \\
Epzicom & GlaxoSmithKline & 446 & $+207 \%$ \\
\hline
\end{tabular}

The pharmaceuticals companies exert massive political influence to protect their profit (Abraham, 2002). In 2001, a coalition of 39 major pharmaceutical companies attempted to prosecute the Government of South Africa, for passing a law that allowed easy production and importation of generics. However, huge outcry from the international community including the South African government, the European Parliament and 300,000 people from over 130 countries who signed a petition against the action, forced the pharmaceutical industry to refrain from such an adventure. One of the pharmaceutical companies involved in the case, GlaxoSmithKline, even granted "voluntary license" to major South African generics producer Aspen to share the rights to their anti-retroviral drugs. This was a significant case as it brought access to medicines for poor countries into the public consciousness.

\section{Selling Fear of Sickness: Profit from Disease Mongering}

The old dictum of "health is wealth" is literally true for profit seeking healthcare industries. There is opportunity to earn big profit even from people who are not sick and are in good health. The social construction of disease as a state of temporary physical or mental condition is being replaced by corporate construction of health as a state of life full of positive energy, desire and fulfillment. The profit seeking industry has learned that there is money to be made in preservation or promise to preserve positive health.

It is now evident that even healthy people are ready to spend money if they can be educated on potential risks of disease and by medicalization of physiology. Medicalization of childbirth has been a real money-spinner for the industry. From the initial confirmation of pregnancy through the event of screening, checkups, and finally, hospitalized childbirth till post partum care has given childbirth the status of the most money making enterprise for the medical industry. To justify better health care by active operative intervention by caesarean delivery method is not acceptable. World over, the rates of caesarean delivery is going high, and in 2009 in the US the rate was $32.3 \%$ of all live births (National Vital Statistics Report, 2011). Though there are newspaper reports regarding profit motives in increasing the number of caesarean sections, but systematic research to nonclinical factors are usually not undertaken. In a study titled The Role of Nonclinical Factors in Cesarean Section Rates in Brazil by Hopkins and Amaral carried out at University of Texas at Austin on pattern of child delivery and operative interventions in Brazilian women, some very interesting points were made (Hopkins \& Amaral, 2005). The study evaluated the 1998 Brazilian census data to arrive at the results. Brazil has one of the highest caesarean section rates (37\%) in the world. It was seen that extraordinarily high rates of above $70 \%$ in private for-profit hospitals contrasted sharply with the not-for-profit public hospitals where the rates were in the $20 \%$ to $30 \%$ range. To analyze various factors like income, education, etc., a multivariate analysis of factors were done in this study, which came out with the conclusion that the nature of organization where a women delivers is the strongest predictor of whether it will be a surgical delivery or not, regardless of her individual characteristics. Ghosh, in 2010, studied the increasing trend in caesarean section delivery in India and role of medicalization of maternal health to infer various factors deciding mode of childbirth (Ghosh, 2010). The conclusion drawn 
was that apart from access to better healthcare system and institutional child delivery facilities, nonclinical factors like medicalization of childbirth, educational and socio-economic status of women are emerging as determinants of mode of childbirth.

Medicalization of aging, physiology and normal phenomenon to earn profit have other examples. Medicalization of baldness is one interesting example. Around the time Merck's hair growth drug finasteride (Propecia) was first approved in Australia, leading newspapers featured new information about the emotional trauma associated with hair loss.

A key strategy of the industry is to use the media with stories designed to create fears about the condition or disease and draw attention to the latest treatment. The sponsoring company provides "independent experts" for these stories, consumer groups provide the "victims", and public relations companies provide media outlets with the positive spin about the latest "breakthrough" medications (Moynihan, Heath, \& Henry, 2002).

Physiological loss of bone mass in elderly women is a risk factor for fractures, but it is definitely not a disease. Pharmaceutical industry is now putting its full effort to turn this risk factor in to a full-fledged disease telling that it needs certain preventive treatment. A medical foundation on osteoporosis, which has received funding from pharmaceutical companies, issued a press release urging people to take a one minute test for the risk of osteoporosis, "we call this disease a silent thief: if you're not vigilant, it can sneak up on you and snatch your quality of life and your long-term health.” (Moynihan, Heath, \& Henry, 2002).

Marketing effort of Glaxo Smith Klines is well known for certain diseases. The stated aim in a communication to their medical writer was "IBS [irritable bowel syndrome] must be established in the minds of doctors as a significant and discrete disease state". Patients also "need to be convinced that IBS is a common and recognized medical disorder". The other main messages for education are about promoting the new "clinically proven therapy"-Lotronex. What for many people is a mild functional disorder-requiring little more than reassurance about its benign natural course-IBS is currently being reframed as a serious disease attracting a label and a drug, with all the associated harms and costs (Moynihan, Heath, \& Henry, 2002).

A new form of disease mongering has infiltrated the public domain, the concept of beauty and health combined to increase the sale of cosmetics and to propagate cosmetic surgery. A more detailed discussion is out of scope of the article, but interested readers can seek insight from a very interesting account of "Cosmetic Gynaecology" that proposes to give aesthetically right private reproductive parts to women who can pay (Lee, 2011).

\section{Packaging for Profit: Case of "Cocktail Vaccines"}

The business emanating from the preventive approach to diseases needs our attention. The marketing of various vaccines originating in developed countries have found large-scale market in the poorer nations, where need of many of the vaccines from a public health perspective remains questionable. The business model here is sensitization of public by the industry involving lobbying physicians, nutrition experts, health care workers to symptoms or disease and their new cures.

Indian physicians have argued against the use of certain vac- cine as recommended by World Health Organization (Puliyel \& Madhavi, 2008). The World Health Organization directive of using pneumococcal vaccine universally based on data and local study carried out in Indonesia and Africa has been critically reviewed in India where there is no local significant burden from this disease in multiple surveillance studies. Indian population has a natural immunity to such infection and the local conditions warrant allocating scarce resources to more important issues at hand. There are nonessential vaccines that tend to piggyback over the essential vaccines, raising both cost and profit.

Over the last few decades, due to the decline of the public sector and the growing disinterest of the private sector, the number of firms supplying the basic vaccines has declined drastically. There is attempted marketing of "value-added cocktail vaccines" at exorbitant prices in the open market. Private for-profit pharmaceutical industries are disinterested to produce the basic vaccines that are cheaper to produce and bring them less money in return. Nevertheless, "formulations where they combine number of vaccines" can be sold at higher prices. The combination of DPT with hepatitis B raises the price of DPT immunization 17 fold. Moreover, the relative safety and efficacy of these cocktail combinations are said to be much lower than their individual components.

\section{Neglecting the Poor Diseases: Avoiding Loss}

People of the western world equate tropical disease with the big three-HIV/AIDS, tuberculosis, and malaria. However, another worrisome group of diseases known as neglected tropical diseases (NTDs) has an even more widespread impact to public health. These neglected tropical diseases occur among populations who live on less than US $\$ 2$ per day or below the World Bank poverty figure of US $\$ 1.25$ per day. The neglected diseases, as notified in World Health Organization literature,

Table 4.

Neglected Diseases as per World Health Organization.
1. Buruli ulcer
2. Chagas disease (American trypanosomiasis)
4. Dengue/severe dengue
5. Dracunculiasis (guinea-worm disease)
6. Echinococcosis
7. Fascioliasis
8. Human African trypanosomiasis
9. Leishmaniasis
10. Leprosy
11. Lymphatic filariasis
12. Onchocerciasis
13. Rabies
14. Schistosomiasis
15. Soil transmitted helminthiasis
16. Trachoma
17. Yaws 
are mentioned in Table 4 (quoted from Trouiller, Olliaro, Torreele, Orbinski, Laing, \& Ford, 2002). The NTDs represent a group of chronic parasitic and related bacterial and viral infections that actually promote poverty. These conditions are of low virulence and may not often kill, but they negatively affect health by causing severe anemia, malnutrition, delays in intellectual and cognitive development, and blindness. Some of these diseases can lead to horrific limb and genital disfigurement and skin deformities and may also increase the risk of acquiring HIV/AIDS.

Other "neglected" conditions: Podoconiosis, Snakebite, Strongyloidiasis were for tropical diseases and tuberculosis (Trouiller, Olliaro, Torreele, Orbinski, Laing, \& Ford, 2002).

$\mathrm{N}$. It was found that there is a 13-fold greater chance of a drug being brought to market for central nervous system disorders or cancer than for a neglected disease. To this effect, the argument from the industry was that research and development for newer compounds are costly and it is risky to invest in lowreturn neglected diseases suffered by people leaving in poor economies. The lack of drug research and development for "non-profitable" infectious diseases will require new strategies from the public policy experts. Currently, there is palpable dearth of interest to control the re-emergence of human African trypanosomiasis, to replace the ineffective and toxic drugs for Chagas' disease, to overcome resistance to antileishmanial and antimalarial drugs, and to develop more effective drugs for tuberculosis to shorten treatment time, and to address multidrug-resistant diseases.

The danger of mixing profit motive with the basic right of health care can rarely cite a better case than this on the perils of unregulated research oriented profit. Millions leave with disease in the global south, where infectious diseases are the killers and modern science is perfectly capable of fighting them, if profit motive vanishes.

\section{Conclusion}

The explicit trend of profiteering over sickness at the behest of the corporate health and pharmaceutical industries is a huge challenge to human civilization and its long cherished goals like universal rights, freedom, and justice. It is now a syndrome of a systemic crisis - a crisis in which largely unregulated healthcare system can produce sickness by a technologically driven culture of diagnosis of diseases. In such a system, the noble efforts of agencies such as World Health Organization, United Nations Development Program or UN Millennium Declaration get completely undermined and marginalized. The profit oriented healthcare care system has so overpowered itself by subduing the natural and universal benefits of scientific discovery, and conventionally perceived power of science and technology to enable human being to confront with odds in day-to-day life has also been sabotaged by the corporate forces. Under such a system, healthcare is degraded into a human body shop, a body shop of engineering and marketing human organs and human disease. The time is up to confront this body shop, which can, however, be done only by radically transforming the healthcare system itself in which health care seekers and not the health care providers will occupy the center stage. Such a transformation will, however, require challenging the global economic and trade regime, which will, of course, be a difficult challenge but not an impossible one.

\section{REFERENCES}

Abraham. J. (2002). The pharmaceutical industry as a political player. Lancet, 360, 1498-1502. doi:10.1016/S0140-6736(02)11477-2

Centre for Disease Controls and Prevention in United States (2011). National Vital Statistics Reports. URL (last checked 12 September 2012). http://www.cdc.gov/nchs/data/nvsr/nvsr60/nvsr60_01.pdf

Cooke, M., Irby, D. M., Sullivan, W., \& Ludmerer, K. M. (2006). American medical education 100 years after the flexner report. New England Journal of Medicine, 355, 1339-1344. doi:10.1056/NEJMra055445

Devereaux, P. J., Schünemann, H. J., Ravindran, N., Bhandari, M., Garg, A., Choi, P. et al. (2002). Comparison of mortality between private for-profit and private not-for-profit hemodi alysis centers: A systematic review and meta-analysis. Journal of American Medical Association, 288, 2449-2457. doi:10.1001/jama.288.19.2449

Davidson, L., \& Greblov, G. (2005), The pharmaceutical industry in the global economy. URL (last checked 12 September 2012).

http://www.bus.indiana.edu/davidso/lifesciences/lsresearchpapers/ph armaceutical\%20industryaug 12 .doc

Ford, N. (2003). Public health and company wealth, British Medical Journal, 326, 1296.

Fortune Magazine. URL (last checked 12 September 2012). $\mathrm{http} / /$ money.cnn.com/magazines/fortune/fortune 500/index.html

Fortune 500 Database. URL (last checked 12 September 2012). http://money.cnn.com/magazines/fortune/fortune500_archive/letters/ P.html

Gagnon, M.-A., \& Lexchin, J. (2008). The cost of pushing pills: A new estimate of pharmaceutical promotion expenditures in the United States. PLoS Medicine, 5, e1. doi:10.1371/journal.pmed.0050001

Garg, P. P., Frick, K. D., Diener-West, M., \& Powe, N. R. (1999) Effect of the ownership of dialysis facilities on patients' survival and referral for transplantation. The New England Journal of Medicine, $341,1653-1660$

Geyman, J. P. (2003).Corporate transformation of medicine and its impact on cost and access to care, The Journal of the American Board of Family Medicine, 16, 443-454.

Ghosh, S. (2010). Increasing trend in caesarean section delivery in India: Role of medicalisation of maternal health. Bangalore: The Institute for Social and Economic Change.

http://www.isec.ac.in/WP\%20236\%20-\%20Sancheeta\%20Ghosh.pdf

Gray, B. H. (1986). For-profit enterprise in health care. Washington DC: National Academy Press.

Hopkins, K., \& Amaral, E. (2005). The role of nonclinical factors in cesarean section rates in Brazil. URL (last checked 12 September 2012).

http://paa2005.princeton.edu/download.aspx?submissionId=50741

Johnston, S., Moss, K., Brown, A. (2011). The business of virtualization in research and development. URL (last checked 12 September 2012).

http://www.oracle.com/us/industries/health-sciences/virtualization-p harma-br-1638314.pdf

Kefauver, E. (1965). In a few hands. Harmondsworth: Penguin.

Lee, M. (2011). Designer vagina surgery: snip, stitch, kerching! URL (last checked 12 September 2012).

http://www.guardian.co.uk/lifeandstyle/2011/oct/14/designer-vaginasurgery

Moynihan, R., Heath, I., \& Henry, D. (2002). Selling sickness: The pharmaceutical industry and disease mongering. British Medical Journal, 324, 886-891.

NIHCM (2002). Changing patterns of pharmaceutical innovation. URL (last checked 12 September 2012). http://www.nihcm.org/pdf/innovations.pdf

Public Citizen (2003). 2002 drug industry profits: Hefty Pharmaceutical Company margins dwarf other industries. URL (last checked 12 September 2012). http://www.citizen.org/documents/Pharma Report.pdf

Puliyel, J. M., \& Madhavi, Y. (2008). Editorial. Indian Journal of Medical Research, 127, 1-3.

Relman, A. S. (1980). The new medical-industrial complex. New England Journal of Medicine, 303, 963-970. 
doi:10.1056/NEJM198010233031703

Relman, A. S. (1997). Market for healthcare: Where is the patient? Clinical Chemistry, 43, 2225-2229.

Starr, P. (1082). The social transformation of American medicine. New York: Basic Books

Thamer, M., Zhang, Y., Kaufman, J., Cotter, D., Dong, F., \& Hernán, M. A. (2007). Dialysis facility ownership and epoetin dosing in patients receiving hemodialysis. The Journal of the American Medical Association, 15, 1667-1674. doi:10.1001/jama.297.15.1667

Treatment action Group (2007). URL (last checked 12 September 2012).

http://www.treatmentactiongroup.org/tagline/2007/september/world wide-antiretroviral-drug-sales-2006

Trouiller, P., Olliaro, P., Torreele, E., Orbinski, J., Laing, R., \& Ford, N.
(2002). Drug development for neglected diseases: A deficient market and a public-health policy failure. The Lancet, 359, 2188-2194. doi:10.1016/S0140-6736(02)09096-7

United States Renal Data System (2206). Excerpts from the USRDS 2006 annual data report. American Journal of Kidney Diseases, 49, S1-S296.

Weintraub, P. (2010). The Dr. who drank infectious broth, gave himself an ulcer, and solved a medical mystery. Discover Magazine. http://discovermagazine.com/2010/mar/07-dr-drank-broth-gave-ulcer -solved-medical-mystery

WHO (2012) List of neglected tropical disease. URL (last checked 12 September 2012).

http://www.who.int/neglected_diseases/diseases/en/ 